\title{
Corrigendum to "Chromosome 3p Inverted Duplication with Terminal Deletion: Second Postnatal Case Report with Additional Clinical Features"
}

\author{
Jacquelyn D. Riley $\mathbb{D}^{1},{ }^{1}$ Catherine M. Stefaniuk, ${ }^{1,2}$ Francine Erenberg, ${ }^{3}$ Angelika L. Erwin, \\ Lauren Palange, ${ }^{4}$ and Caroline Astbury $\mathbb{D}^{1}$ \\ ${ }^{1}$ Molecular Pathology Section, Pathology and Laboratory Medicine Institute, Cleveland Clinic, Cleveland, OH, USA \\ ${ }^{2}$ Department of Pathology and Laboratory Medicine, University of Cincinnati Health, Cincinnati, OH, USA \\ ${ }^{3}$ Pediatric Cardiology, Pediatric Institute, Cleveland Clinic, Cleveland, OH, USA \\ ${ }^{4}$ Center for Personalized Genetic Healthcare, Genomic Medicine Institute, Cleveland Clinic, Cleveland, OH, USA \\ Correspondence should be addressed to Caroline Astbury; astburc@ccf.org
}

Received 18 September 2019; Accepted 1 October 2019; Published 24 November 2019

Copyright (c) 2019 Jacquelyn D. Riley et al. This is an open access article distributed under the Creative Commons Attribution License, which permits unrestricted use, distribution, and reproduction in any medium, provided the original work is properly cited.

In the article titled "Chromosome 3p Inverted Duplication with Terminal Deletion: Second Postnatal Case Report with Additional Clinical Features" [1], the first and third affiliations were incomplete. The corrected authors' list and affiliations are shown above.

\section{References}

[1] J. D. Riley, C. M. Stefaniuk, F. Erenberg, A. L. Erwin, L. Palange, and C. Astbury, "Chromosome $3 p$ inverted duplication with terminal deletion: second postnatal case report with additional clinical features," Case Reports in Genetics, vol. 2019, Article ID 5384295, 7 pages, 2019. 


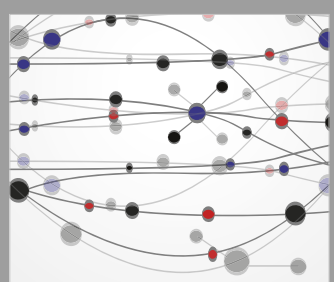

The Scientific World Journal
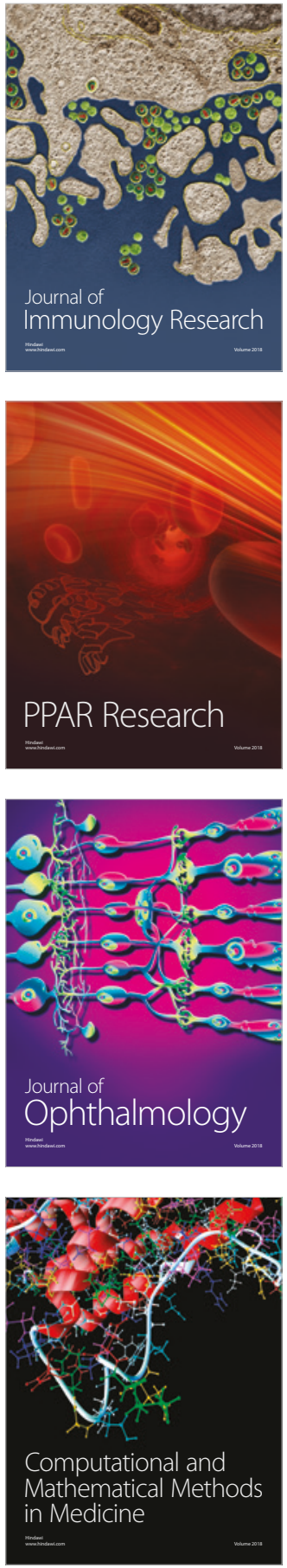



Gastroenterology Research and Practice



\section{Hindawi}

Submit your manuscripts at

www.hindawi.com
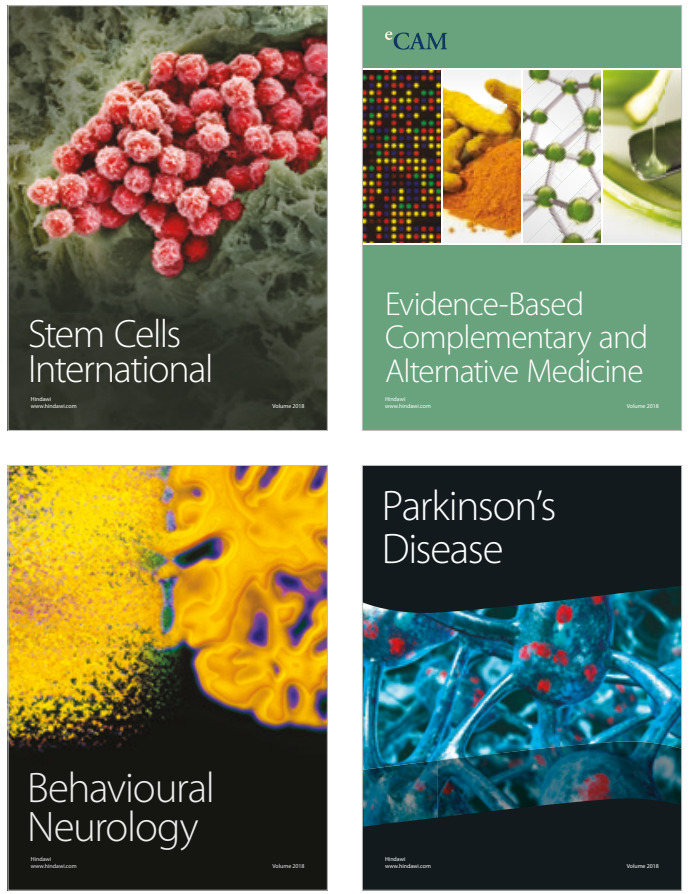



ournal of

Diabetes Research

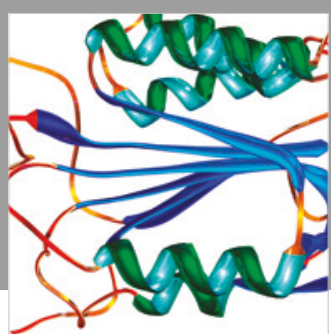

Disease Markers
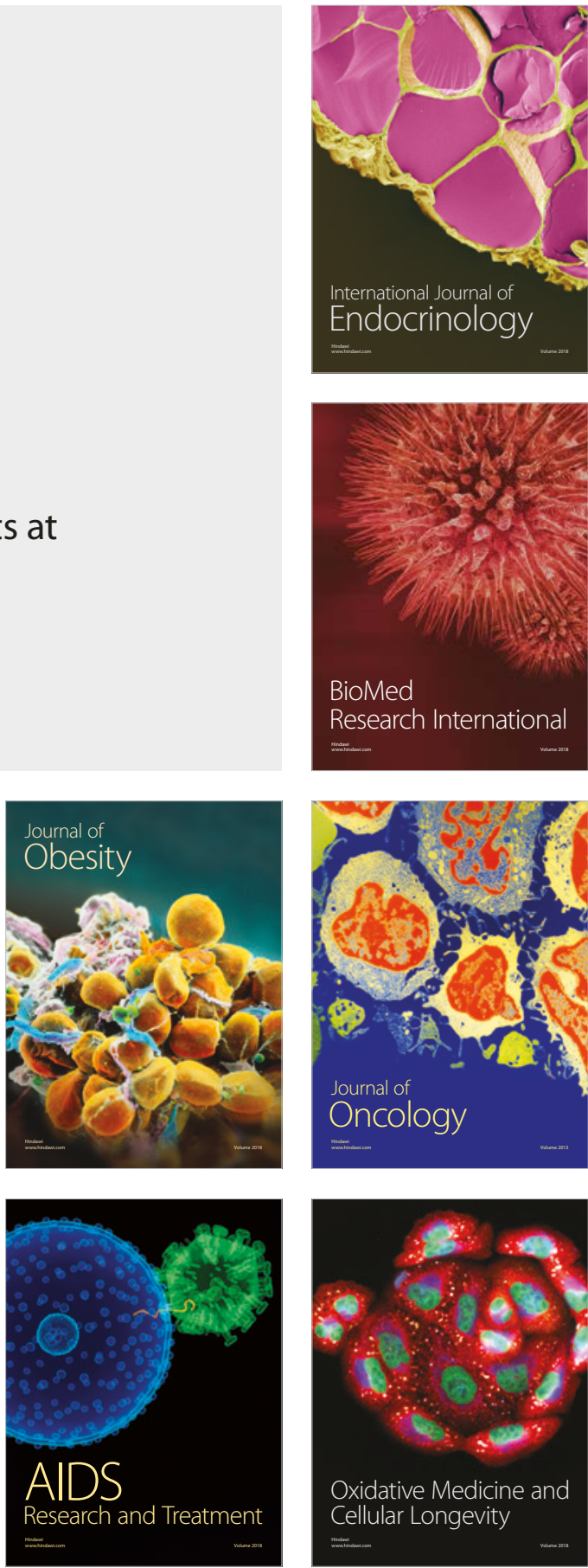